\title{
Políticas Educativas e a Gestão dos Modos de Viver nas Cidades
}

\author{
Rodrigo Manoel Dias da Silva' \\ Chaiane Paula Busnello' \\ Fabíola Pezenatto'
}

'Universidade Federal da Fronteira Sul (UFFS), Chapecó/SC - Brasil

RESUMO - Políticas Educativas e a Gestão dos Modos de Viver nas Cidades. O artigo propõe-se a verificar a efetuação das políticas educativas e suas possibilidades de gestão, em cenários de fragilização de dispositivos institucionais. Para tal, revisa as relações entre políticas educativas e gestão dos modos de vida em reformas urbanas do início do século XX, assim como analisa o modelo moderno que configurava as institucionalidades, seu declínio e suas possibilidades de mudança. A seguir, realiza uma inflexão analítica para compreender estes fenômenos políticos no Brasil, a partir de projetos políticos para a educação em tempo integral, onde reconhece modos de gestão dos processos formativos de indivíduos e de seus modos de vida. Conclui que a fragilização das instituições permite a recomposição de narrativas de sentido social, o que constitui desafios à gestão escolar. Palavras-chave: Políticas Educativas. Instituições de Ensino. Educação Integral. Gestão Escolar.

ABSTRACT - Educational Policies and Management of the Modes of Living in Cities. The paper proposes to verify the effectuation of educational policies and their management possibilities in scenarios weakening of institutional arrangements. To this end, reviews the relationship between education policy and management modes of life in urban reforms of the early twentieth century, as well as the modern model that analyzes the institutionalities configured, decline and change. Then came the unfolding of political phenomena in Brazil, in projects of integral education, where we can see ways of managing the training processes of individuals and their life styles. It concludes that the weakening of institutions allows the reconstruction of narratives of social meaning, which brings challenges for school management.

Keywords: Educational Policies. Educational Institutions. Integral Education. School Management.

Educação \& Realidade, Porto Alegre, v. 38, n. 3, p. 953-975, jul./set. 2013. 953 Disponível em: <http://www.ufrgs.br/edu_realidade> 
Políticas Educativas e a Gestão dos Modos de Viver nas Cidades

As análises sociológicas recentes sobre a escola se preocupam com a atual configuração de seus dispositivos institucionais (Dubet, 2004; 2007) e das condições que oportunizam aos múltiplos atores escolares para a construção de suas formas de ação. Há toda uma tradição no pensamento social francês, especificamente, preocupada em reconhecer, analisar e discutir as relações sociais possíveis de serem estabelecidas entre estes atores e os determinantes sociais próprios das instituições modernas que lhes potencializam e circunscrevem, consubstanciados por instrumentais de políticas educativas.

Na leitura que fazemos, estas primeiras políticas educativas, típicas da transição do século XIX ao XX, possuíam três características fundamentais, sendo estas: estabeleciam diretrizes claras à formação de indivíduos ajustados aos padrões de uma civilização em mudança; vislumbravam um âmbito mais alargado às iniciativas das políticas educativas, nem tanto dirigidas às instituições escolares, mas situadas nas crescentes aglomerações citadinas; e objetivavam contribuir para a produção de identidades nacionais homogêneas e coerentes, tomando a educação dos indivíduos como pressuposto à construção da nação. Portanto, as políticas educativas estavam imbuídas da tarefa de gerir os modos de viver nas cidades, uma vez que tanto suas intervenções estruturais, quanto suas ações instrutivas, engendravam interesses civilizadores (Elias, 2011).

No entanto, este modelo forte de ação institucional, desde meados da década de 1980, vem demonstrando fragilidades e diversas análises têm apontado para novas experiências e vivências em curso nos ambientes escolares, algumas vezes interpretando a sensação de crise da escola (Momo; Costa, 2009), outras atentas às novas identidades institucionais emergentes nestes cenários (Cavaliere, 2002), ou mesmo na evidente multiplicação de projetos políticos-culturais que tomam as escolas como um público privilegiado, sob a égide de produzir-lhe novos sentidos e novas práticas. Em todo caso, afora diversas possibilidades sociológicas de leitura destes fenômenos, pensamos que há inúmeros fios de mudança social em movimento na escola contemporânea, observados por seus analistas e sentidos de maneiras variadas por seus agentes. Não obstante, as sensações de mudança existem. Diante dessa percepção, originada de atividades investigativas etnográficas, mas amadurecida por continuados olhares à literatura, optamos por analisar um destes fios da mudança social, qual seja: os nexos entre as políticas educativas e a gestão dos modos de viver nas cidades. Nossa principal problematização, neste texto, reside em verificar como se efetuam estas políticas e suas possibilidades de gestão, em cenários de fragilização de dispositivos institucionais.

Para tal fim, segmentaremos didaticamente a sequência deste artigo em quatro seções textuais. Na primeira, realizaremos uma revisão dos antecedentes históricos desta relação entre políticas educativas e gestão dos modos de vida na ambivalente condição das reformas ur- 
banas do início do século XX, onde as políticas da educação estavam a todo tempo associadas à vida citadina, de maneira que reforma nas cidades e reforma na conduta dos indivíduos tornava-se o binômio fundamental destas práticas. Na segunda, analisaremos como este modelo integrador moderno que configurava as institucionalidades entra em declínio e cria possibilidades mais evidentes de mudança nas escolas, assim como novos agenciamentos culturais passam a plasmar-se em seu interior, com novas dinâmicas e sentidos. Na terceira, acompanharemos o desdobramento destes fenômenos políticos no Brasil, interessados em verificar a emergência de projetos de educação em tempo integral, onde, em seus três momentos históricos, se torna perceptível distintos modos de gestão dos processos formativos de indivíduos e de seus modos de vida. Na última, concluímos reiterando que a fragilização das instituições modernas permite a recomposição de narrativas de sentido social, o que traz novas pautas à gestão e às políticas escolares, em nosso tempo.

\section{Reforma nas Cidades, Reforma na Conduta dos Indivíduos}

No começo do século XX, filantropos, assistentes sociais, reformadores de moradias e os primeiros urbanistas defrontavam-se com o objetivo imediato de transformar as realidades das metrópoles do mundo industrial, de modo que sua visão estratégica tomava por pressuposto fundamental o interesse em "[...] mudar a cidade para mudar a sociedade e, particularmente, o povo" (Topalov, 1996, p. 23). Esses processos de reforma social não eram fenômenos isolados, pois, desde 1880, inúmeras iniciativas de atores e governos locais vinham sendo operacionalizadas na Europa e na América do Norte com a pretensão de atenuar os efeitos da ainda recente Revolução Industrial. A sociedade e a cidade tornavam-se objetos de ação racional e sistemática de uma estrutura de Estado, o que inaugurou modelos de políticas urbanas no contexto, assim como a população passou a ser objeto regular de intervenções públicas de cidadania, consubstanciado pela consolidação das políticas sociais modernas. Em todo caso, parece-nos que tal situação inaugurou formas de relacionamento entre o Estado e a população, o que, como sabemos, não ocorreu isenta de tensões, clivagens e disputas.

As iniciativas projetadas pelos reformadores estavam mesmo dirigidas ao povo, sendo descritas na literatura intervenções para a contenção do desemprego, a manutenção dos trabalhos assalariados e a construção de casas populares (Topalov, 1996). No contexto francês, por exemplo, Henry Sellier, então prefeito socialista de um subúrbio de Paris, desenvolveu relevante papel na reforma das habitações no país, uma vez que, antes da Primeira Guerra Mundial, assinalava a necessidade da criação de um órgão público para construção de casas populares na área do Sena, com uma alegação que merece nossa atenção:

Educação \& Realidade, Porto Alegre, v. 38, n. 3, p. 953-975, jul./set. 2013.

Disponível em: <http://www.ufrgs.br/edu_realidade> 
Políticas Educativas e a Gestão dos Modos de Viver nas Cidades

A cidade [...] e as condições de moradia exercem uma influência decisiva sobre a mortalidade e a educação do povo. É preciso afastar trabalhadores dos prazeres grosseiros da cidade e da fascinação da rua, dos bares e boates (Sellier apud Topalov, 1996, p. 26).

O enunciado do político socialista francês nos indica o moralismo tradicional, registrado em outros registros sociológicos sobre o país, mas, principalmente, que atribui à educação um papel fundamental na transformação dos modos de viver na cidade. Supunha Sellier que "[...] o progresso social exige uma mudança radical nos costumes dos operários, e essa mudança não depende apenas da moradia, mas, também, das condições globais da vida urbana" (Topalov, 1986, p. 26). Assim, tornou-se evidente que a planificação reformadora daquelas cidades dependia de projetos educativos assentados na preocupação em ensinar os trabalhadores a viver na cidade, com melhores hábitos pessoais, com vida comunitária saudável, sem alcoolismo e outros vícios, com auspiciosos cuidados sobre suas residências. Tais metas permitiram a idealização de uma cidade-jardim. Condições de ventilação, de luminosidade, de beleza e de novas relações sociais mais salutares tornavam-se a materialização do ideal político-educativo implementado. De certo, os primeiros programas políticos de intervenção nas cidades orientavamse por projetos de infraestrutura, ordenando-as desde matrizes ideológicas e arquitetônicas com base em uma cosmovisão ocidental, caso do Positivismo Comteano, mas, ao mesmo tempo, imbuídos de planificações voltadas à reforma das condutas dos cidadãos sob visível interesse civilizador.

O imperativo político de intervir nos universos humanos mediante dispositivos pedagógicos, seguramente, não foi inaugurado no início do último século. Erasmo de Rotterdam, ainda em 1530, publicou De Civilitate Morum Puerilium (Da Civilidade em Crianças), obra esta de grandiosa circulação, em suas diversas edições, que tornou-se um catecismo da educação dos meninos, sendo reeditada até meados do século XVIII. Este tratado, um tanto insignificante no conjunto da obra do filósofo, torna-se “[...] sintoma de mudança”, ou “[...] uma concretização de processos sociais" (Elias, 2011, p. 68), em curso. A ideia-título do livro, ao metamorfosear-se, pela linguagem, em civilidade (civilité), torna-se condição de “[...] expressão fundamental de autointerpretação da sociedade europeia” (Elias, 2011, p. 60). Erasmo, todavia, trata de um tema singelo a seu tempo, qual seja: o comportamento social das pessoas, ou “[...] do decoro corporal externo" (Elias, 2011, p. 69), no qual se dedica a proceder reflexões simples, em linguagem ora polida, ora irônica, sobre costumes e atitudes dos indivíduos na coletividade. Ainda dimensiona normatizações aos comportamentos mais íntimos, como os modos de olhar, a postura, os gestos, o vestuário, o portar-se à mesa ou as expressões fisionômicas, quando as mesmas ressoam em comportamentos externos. Assim, vai tecendo condutas sociais que primam pela assepsia corporal, o rigor nos gestos e a atenção no conviver socialmente.

956 Educação \& Realidade, Porto Alegre, v. 38, n. 3, p. 953-975, jul./set. 2013 Disponível em: <http://www.ufrgs.br/edu_realidade> 
Como observa Norbert Elias, muitas das lições do filósofo, considerando necessárias traduções temporais, ainda são ditas e ensinadas com o interesse de tornar o homem "civilizado". Assim é apresentada a obra em questão:

Com grande cuidado, Erasmo delimita em seu tratado toda a faixa de conduta humana, as principais situações da vida social e de convívio. Com a mesma naturalidade fala das questões mais elementares e sutis das relações humanas. No primeiro capítulo, trata das 'condições decorosa e indecorosa de todo o corpo', no segundo da 'cultura corporal', no terceiro de 'maneiras nos lugares sagrados', no quarto em banquetes, no quinto em reuniões, no sexto nos divertimentos, no sétimo no quarto de dormir (Elias, 2011, p. 69).

Mesmo sem um maior detalhamento da obra de Erasmo, feita por Elias (2011), torna-se conveniente destacarmos que suas expressões acompanham todo um processo civilizador que ocorreu no Ocidente (Elias, 2011). Assim, mudanças educativo-culturais nos costumes humanos, embasadas na moralização de suas condutas, replicariam nos destinos políticos imbricados em mecanismos de produção de uma civilização mais desenvolvida, encontrando uma multiplicação intensa no começo do século XX. O mundo europeu moderno naturalizou as prerrogativas civilizacionais, tornando-as motivo de posse ou status, tomando-as como demonstrações de ilustração e superioridade cultural, ao mesmo tempo em que mantinha nas instituições de ensino mecanismos e processos de civilização reguladores da "vida instintiva", como assinalara Erasmo (apud Elias, 2011, p. 68). Portanto, todo esse processo histórico de longa duração, permite-nos analisar que as transformações nas condutas humanas estavam associadas a transformações nas ações das instituições públicas, como o Estado, por exemplo, em suas prerrogativas de ação e poder.

Quanto aos indivíduos, essas reformas em suas condutas, segundo Elias, estavam vinculadas a algumas características, como: o abrandamento das pulsões humanas, a homogeneização das diferenças entre os homens e a integração em padrões de convivência social adequados ao padrão civilizacional esperado. Neste sentido, idealizava-se que o indivíduo transitasse de um estágio formativo em que dependia do controle e da regulação de outros (pessoas e instituições), para estágios de autocontrole e de vigilância de si mesmo. Os imperativos civilizadores operavam sobre a formação psicológica e moral dos indivíduos, garantidos por mecanismos punitivos externos, ou por constrangimentos autoimpostos como a vergonha ou a repugnância de determinados comportamentos ou o medo em transgredir algumas proibições sociais (Elias, 1993).

Estes princípios civilizacionais, de algum modo, operavam sob princípios coercitivos de fabricação de homogeneidade social, ao es- 
Políticas Educativas e a Gestão dos Modos de Viver nas Cidades

tabelecer padrões de normalidade (Durkheim, 1987) e fixar teleologias desejáveis aos potenciais cidadãos modernos, isto é, a gestão dos desafios urbanos modernos no cenário posterior à Revolução Industrial dependia de reordenamentos dos espaços sociais e a regulação das forças plurais (Simmel, 1946) presentes na sociedade. Assim, os usos da educação estavam associados ao projeto de civilização em voga, mas tomando-a em acepções moralizadoras ao circunscrever as instituições de ensino a padrões rigorosos de relacionamento entre seus agentes e dos mesmos com os aportes epistemológicos e socioculturais de seu tempo. A educação e, particularmente, suas políticas associam-se ao projeto socializador moderno.

As políticas educativas implementadas, sobretudo na transição dos séculos XIX e XX, obtiveram duas responsabilidades primordiais: a primeira, a gradativa universalização do ensino laico e público, com a pretensão de elevar o nível cultural das camadas populacionais economicamente desfavorecidas, aproximando-as dos padrões de civilité e reduzindo as diferenças culturais entre a elite e o povo; e, a segunda, consolidar processos de identificação dos indivíduos ao Estado Nacional, através do fortalecimento de sentimentos de pertença, a difusão de princípios valorativos de igualdade (Dubet, 2003) e acomodação das ambiguidades modernas situadas entre a construção de igualdade democrática e as desigualdades inerentes a formações sociais capitalistas (Dubet, 2003). Como vemos, as políticas em implementação associavam, mesmo que não racional e intencionalmente (Elias, 1993), os nexos instituídos entre civilização, intervenções urbanas e ações educativoculturais.

Neste sentido, a escola assumiu sua função de instituição socializadora, que define o ator social por sua potencialidade em incorporar os valores e normas da sociedade de seu tempo. Em seus cursos de ação, o ator incorporaria os princípios estáveis e homogêneos do sistema, logo o ator se tornaria o sistema (Dubet, 1994). Mesmo perspectivas de orientação crítica não negaram a condição de socialização das instituições de ensino, mas foi na vertente político-sociológica funcionalista que estas afirmativas encontrariam sua gênese e seu desenvolvimento mais evidenciados. Os sentidos da educação estavam muito próximos das formulações de Kant e Durkheim.

Apesar de considerar a definição de educação de Kant, de certa forma, idealista, Émile Durkheim não a remove plenamente de seu horizonte de preocupações investigativas. Segundo Kant, o fim da educação seria o desenvolvimento, em cada indivíduo, de toda perfeição de que este seja capaz. Na visão kantiana, pois, perfeição é o desenvolvimento harmônico de todas as faculdades humanas (Durkheim, 1987).

A leitura de Durkheim, por sua vez, enfatiza que a sociedade não existiria sem que houvesse em seus membros certa homogeneidade, sendo função da educação a perpetuação e o reforço dessa homogeneidade, o que implicaria a fixação na criança de alguns comportamentos 
necessários à vida coletiva. Ao mesmo tempo, sem um mínimo de diversificação toda cooperação ou forma de solidariedade seria impossível: é a diversificação que permite a especialização da sociedade. Essa, portanto, seria a definição central do processo de socialização no quadro do Funcionalismo: a presença das funções diferenciadora e homogeneizadora das relações sociais. Nessa perspectiva, educação:

É a ação exercida pelas gerações adultas sobre as gerações que não se encontram ainda preparadas para a vida social; tem por objeto suscitar e desenvolver, na criança, certo número de estados físicos, intelectuais e morais, reclamados pela sociedade política no seu conjunto e pelo meio especial a que a criança, particularmente, se destine (Durkheim, 1987, p. 42).

O mesmo pensador francês, em sua definição de educação, revelou ressonâncias das três características do fato social que enunciara anteriormente. Quando mencionou que a educação é uma ação exercida por uma geração sobre outra, denota sentidos de coercitividade; ao mesmo tempo, quando citou acima que a educação é a ação de desenvolver determinados estados em alguém imaturo, propôs elementos de exterioridade e, em igual teor, quando menciona que o fenômeno educativo ocorre em um meio específico, reitera seu caráter de objetividade. Assim, as demarcações de objetividade, coercitividade e exterioridade, típicas de sua noção de fato social, caracterizam seu conceito de educação. Além disso, a educação é interpretada como um processo linear, contínuo, de normas sociais homogêneas e produtoras de funcionalidades ao sistema social o que denotaria todo o caráter social da educação na modernidade.

As características do fato social de Durkheim são elementos significativos na definição de instituição social de Peter e Brigitte Berger. Consoante à elaboração dos autores, partimos da ideia de que toda instituição social seja uma forma de objetivação da realidade, pois no fluxo das experiências sociais ela se torna dotada de exterioridade, objetividade e coercitividade, além de autoridade moral e historicidade (Berger; Berger, 1977). A exterioridade refere-se ao fato de uma instituição social ser experimentada como algo dotado de realidade exterior ao indivíduo, diferindo-se da realidade formada por seus sentimentos, pensamentos ou fantasias. A objetividade, por sua vez, refere-se à existência material da instituição.

As instituições são dotadas de força coercitiva:

Em certa medida, esta qualidade está implícita nas duas que já enumeramos: o poder essencial que a instituição exerce sobre o indivíduo consiste justamente no fato de que a mesma tem existência objetiva e não pode ser afastada por ele. No entanto, se acontecer que este não note o fato, esqueça o mesmo ou, o que é pior -, queira modificar o estado de coisas existente, é nessas oportunidades que muito provavelmente a força coercitiva da instituição se apresenta de forma bastante rude (Berger; Berger, 1977, p. 197).

Educação \& Realidade, Porto Alegre, v. 38, n. 3, p. 953-975, jul./set. 2013

Disponível em: <http://www.ufrgs.br/edu_realidade> 
Políticas Educativas e a Gestão dos Modos de Viver nas Cidades

A dimensão coercitiva da instituição caracteriza-se pela garantia da homogeneidade da ordem social. O que não significa que não ocorram mudanças, as instituições mudam constantemente para garantir seus resultados de ação e controle, tanto quanto em suas intervenções na urbanidade. Esse efeito de manutenção não se dá unicamente pela coercitividade, mas por sua autoridade moral. Toda instituição social exige seu direito à legitimidade, reservando-se ao direito de repreender o indivíduo que viola suas normas e regras morais. Essa última caracterização das instituições sociais, a nosso ver, revela uma fissura com o marco funcionalista, pois propõe que a instituição tem a qualidade da historicidade, não constituída apenas por fatos, mas por fatos históricos.

Para uma necessária definição da escola como uma instituição social, além das características acima citadas, implica verificarmos sociologicamente elementos de sua estrutura, tal como realizaram Cândido (1971) e Znaniecki (1971). Quando, no fim dos anos de 1940, Florian Znaniecki indicava um caminho analítico à compreensão dos processos sociais ocorridos no seio das instituições de ensino, inaugurava uma nova e significativa perspectiva de interpretação sociológica da escola como um grupo instituído. Tal concepção empregava o termo grupo instituído para designar, então, determinados agrupamentos que seriam, por excelência, produtos da cooperação entre seus membros, mas cujas posições e funções na coletividade seriam instituídos por outros grupos sociais (Znaniecki, 1971). Esta abordagem afirmava que o grupo instituído, necessariamente, não seria determinado por outro que fosse, nestes termos, o instituidor, mas teria um espaço de negociações entre ambos com provável prevalência do último.

Dentro do campo heurístico elaborado por Znaniecki, poderíamos tomar então a escola como referência, uma vez que "[...] toda escola consiste num grupo social, com uma composição definida, e uma organização e uma estrutura, ainda que rudimentares" (Znaniecki, 1971, p. 105). Neste caso, sua existência dependeria das atividades associadas entre seus membros - genericamente - professores e alunos, o que determinaria seu caráter autônomo; mas, por vezes, a escola se faz sancionada por outros grupos sociais: o Estado, grupos religiosos, grupos territoriais ou diversos grupos culturais. Outras escolas, segundo o mesmo autor, são instituídas por determinadas categorias profissionais ou por grupos econômicos. Mas, em todo caso, destaca que:

[...] uma escola, enquanto grupo social, conserva um certo grau de autonomia interna, uma ordem específica própria, semelhante à de muitas outras escolas, mas diferentes da de grupos de uma outra categoria, pois o papel dos professores e dos alunos diferem essencialmente do papel dos membros de qualquer outro grupo (Znaniecki, 1971, p. 106).

Independentemente das expectativas sociais depositadas na educação, ou de suas operatividades políticas mais rígidas ou mais nego- 
ciadas, o processo civilizador moderno mobiliza um projeto formativo, onde estão em jogo os potenciais de intervenção do Estado sobre a população e a afirmação de processos identitários de construção dos próprios indivíduos. Este projeto formativo exigia a organização dos procedimentos pedagógicos, o gerenciamento das experiências sociais dos atores e a recursiva produção sistêmica dos instrumentos administrativos e burocráticos, o que reverberava na padronização dos agenciamentos sociais e culturais (Silva, 2012) e na produção de determinantes e diretrizes à ação do Estado nos espaços urbanos. Em suma, estas intervenções estatais estabeleciam que as reformas urbanas deveriam associar-se às reformas nas condutas dos indivíduos. Porém, as referências modernas de institucionalidade não encontraram a desejada perseverança histórica e, poucas décadas a seguir, alguns cientistas sociais passaram a narrar e interpretar alguns indícios de seu declínio, como veremos na seção textual a seguir.

\section{O Declínio da Institucionalidade da Escola}

Segundo Silva (2008), a perspectiva de Znaniecki, sobre a escola como grupo instituído, se torna analiticamente útil quando contrastada com a produção das sociabilidades no mesmo espaço social (Cândido, 1971). A ambiguidade entre a institucionalização e a produção das sociabilidades na escola produz brechas para a negociação das autonomias dos atores no âmbito destas relações sociais. Naquele quadro, o autor afirmou que as políticas escolares, sobretudo aquelas atreladas à efetividade dos mecanismos de participação política, são constituídas em práticas culturais de negociação pelos usos destes espaços, o que implica formulação e definição de agendas por meio de mobilizações sociopolíticas. Embora tal pesquisa tenha reafirmado o peso da institucionalização na definição destas agendas, pois se evidenciaram expressões de participação não-autônomas nestas dinâmicas (Silva, 2008), demarcou que sua vigência não estava assentada em princípios homogêneos ou contínuos, mas em lógicas de ação heterogêneas e diversificadas produzidas desde a experiência (Dubet, 1994) dos atores sociais envolvidos.

Estes espaços de negociação (endógenos e exógenos) das normas escolares são produzidos quando identificamos a conflitualidade das mesmas, o que permite considerarmos o ocaso do marco funcionalista de entendimento da escola como instituição social, portanto uma instituição linear, contínua e rígida.

Diante de semelhante percepção, inúmeros autores têm interpretado o declínio da institucionalidade da escola e apontam mudanças em seus fazeres políticos e pedagógicos, tanto quanto outros sinalizam suas consequências. François Dubet (2007) quando analisa a situação destaca como principal consequência a fragilidade dos princípios estruturadores das instituições de ensino, quais sejam: valores sagrados, vocação 
Políticas Educativas e a Gestão dos Modos de Viver nas Cidades

docente, escola como santuário e liberação através da disciplina. Quando, portanto, seus valores fazem-se profanos, seus docentes tornam-se profissionais, seus espaços perdem as prerrogativas de exclusividade do saber universal e suas normas rígidas esmaecem em múltiplas negociações, algo inevitavelmente muda nas instituições de ensino.

A fragilização dos dispositivos institucionais modernos observados nas instituições de ensino, sobretudo em suas conhecidas estratégias de fabricação unilateral de identidades sociais, ou em seus mecanismos de controle do corpo e da mente de seus estudantes, permitiu a circulação de múltiplas discursividades em seu interior, assim como novas práticas socioculturais passaram a ocupar-lhe. Evidentemente que estas novas narrativas escolares não estão desprovidas de hierarquias, clivagens ou interesses, pelo contrário, evidenciam-se novos jogos de relações políticas, socioeconômicas e pedagógicas, ou seja, políticas culturais passam a transitar por seus frágeis dispositivos institucionais. Assim, não supomos que as finalidades educativas modernas depositadas nas escolas esmaeceram, ou que se tornaram destituídas de seus potenciais de regulação social, mas passaram a conviver com outros dispositivos culturais de deliberação (Dewey, 1970), na razão em que estabelece a potencialização de um campo valorativo de democratização da cultura, na escola.

Acompanhando as reflexões de John Dewey, observamos a inexistência de uma plena democratização destas entidades sociais, porém, mesmo que a presença de técnicas de vida produza novas formas de controle e regulação das práticas culturais, plasma-se um novo campo de valores democráticos, pois não há grupo social sem a existência de “[...] valores apreciados em comum” (Dewey, 1970, p. 105). Neste cenário, frente à fragilização dos dispositivos institucionais, a escola passa a ser um espaço de "[...] sujeitos em trânsito" (Tofler, 1964, p. 80), onde os agentes, suas práticas, suas discursividades e seu estar-no-mundo mobilizam-se. Tal situação de transitividade permite a irradiação de agenciamentos culturais, tal como fluxos de sentido que lhe atravessam (e instituem) em múltiplas direções (Silva, 2012).

Essa irradiação de agenciamentos culturais na escola contemporânea permite-nos compreender a presença constante de projetos e políticas culturais, de iniciativas pública e privada, em seu interior. No cenário histórico da educação brasileira, os projetos políticos de ampliação da jornada escolar ou de educação em tempo integral, especificamente em seus três momentos mais significativos, parecem produzir narrativas de reconstrução valorativa face o declínio da institucionalidade das escolas. Isso, portanto, indica que cada uma das propostas nacionais de educação em tempo integral pretenderam responder de maneira diversa a projetos societários mais amplos, como a superação das desigualdades sociais ou a produção de ideologias de desenvolvimento nacional. 


\section{Os Projetos de Educação Integral em Tempo Integral no Brasil}

O percurso institucional da educação no Brasil, iniciado por volta do século XVIII, com a presença dos ideais iluministas, revelou propósitos modernos de difusão de modelos de apropriação, assimilação e transmissão dos saberes escolares pautados por perspectivas empiristas e utilitaristas. Ao mesmo tempo, a escola moderna trazia em si projetos civilizatórios, na acepção de Norbert Elias, nos quais seu conteúdo previa a "[...] transformação do comportamento humano" (Elias, 2011, p. 68), de certo modo, uniformizando as identificações nacionais, os idiomas e as funções das nascentes formações sociais.

A exemplo do contexto europeu, em que o conceito de civilização plasmava a sociedade de corte (Elias, 2011), a educação brasileira esteve interessada na formação dos indivíduos, ora voltada à produção de um ensino próprio a manutenção do poder das elites locais, consubstanciada em interesses clientelistas e patrimonialistas (Carvalho, 2011), ora interessada na elevação moral e intelectual das camadas populacionais mais pobres e mais distantes das metrópoles urbanas. Em todo caso, por uma história das políticas educacionais, no país, é possível constatarmos que seus objetivos apontam para conjugações deste duplo compromisso social: manutenção das relações político-culturais instituídas e provimento de programas de alfabetização e escolarização básica a densos contingentes populacionais.

Nesse contexto, o analfabetismo e os insignificantes indicadores de acesso, permanência e qualidade formativa foram vistos como obstáculos ao progresso do país. Havia uma incompatibilidade entre os nascentes desejos de urbanização e industrialização e as realidades escolares dos mais diversos lugares do Brasil. A educação passou a ser uma questão fundamental para civilizar a população.

Escolarizar massivamente era a grande narrativa das políticas brasileiras para a educação. O começo do século XX e, com efeito, o início da década de 1920 ficou marcado pela instalação de escolas e sistemas educativos públicos, de igual maneira pela experimentação de reformas e planos de qualificação do setor. Segundo Cavaliere (2003), o principal dilema destas reformas dizia respeito aos conflitos entre expansão e qualidade dos sistemas educacionais. As intervenções políticas consequentes destas iniciativas, caso da Reforma Educacional Paulista de 1920 (Cavaliere, 2003), organizavam-se em torno dos dilemas atinentes à qualidade versus quantidade. Remover os obstáculos da ignorância e implementar um processo de civilização que construísse as bases para o desenvolvimento do país exigia o enfrentamento desse dilema. No caso da reforma paulista, a solução encontrada foi a priorização da alfabetização (como projeto coletivo) em um curso primário de dois anos de duração e duas horas e meia de aula (Cavaliere, 2003).

Educação \& Realidade, Porto Alegre, v. 38, n. 3, p. 953-975, jul./set. 2013.

Disponível em: <http://www.ufrgs.br/edu_realidade> 
Políticas Educativas e a Gestão dos Modos de Viver nas Cidades

Tal situação, revelava-nos que o projeto de civilização em voga não era consensual. Anísio Teixeira e um conjunto de intelectuais brasileiros denunciavam que este modelo educacional mantinha a educação como privilégio (Teixeira, 1977). A qualidade dos processos formativos estava intimamente vinculada com o tempo de permanência dos estudantes na escola. Se, de fato, a transposição dos interesses civilizadores europeus não se deu de modo natural ao caso brasileiro, a retomada das discussões sobre educação integral e educação em tempo integral lhe impõe mediações mais complexas. Não se tratava apenas de elevar moralmente os valores e construir comportamentos e condutas apropriadas a um novo modo de viver nas cidades, a educação brasileira estava intrinsecamente vinculada a objetivos sociais mais amplos.

Para ilustrar tal entendimento, estaremos verificando três momentos específicos das políticas educativas brasileiras, onde o interesse por concepções e práticas de educação em tempo integral ${ }^{1}$ foram reconstruídos com a finalidade de sedimentar e promover uma interpretação sobre os problemas do país e projetar iniciativas em direção a sua resolutividade, muitas vezes, através de planos de intervenção que alargaram o entendimento de educação para além das ações escolares objetivando mudanças sociais em coletividades. Então, o projeto da Escola Parque de Anísio Teixeira, os Centros Integrados de Educação Pública (CIEPs) idealizados por Darcy Ribeiro e o Programa Mais Educação criado e gerido no Governo Lula seriam expressões de projetos educacionais diversos, que projetam relações novas relações entre a educação e os modos de viver nas cidades brasileiras.

A educação em tempo integral interpretada como possibilidade de “[...] formação global dos indivíduos" (Cavaliere, 2002, p. 250), assumia um notável interesse político em revisar e projetar novas modalidades político-culturais para a administração escolar, em suas diversas escalas, associadas a um plano nacionalista de moralização e produção de uma nova ordem social, como expõe o fragmento a seguir:

Percebe-se que, por meio desses mecanismos, a escola primária começa a funcionar como um sistema de ensino que, acima de qualquer coisa, se impõe enquanto um poder regenerador que tem a função de moralizar, civilizar e consolidar a ordem social; ou seja, essa escola, além de se estabelecer produzindo uma série de inovações pedagógicas, nasce comprometida com os ideais republicanos que buscam a consolidação de uma nação moderna e industrializante (Chaves, 2002, p. 45).

Essa nova escola brasileira nas primeiras décadas do século XX ajustava-se a projetos de construção de uma nação desenvolvida, urbana e industrial. Segundo o sociólogo Luiz Pereira, a etapa contemporânea da história brasileira inicia nesse período (Pereira, 1970), onde amplas transformações econômicas, políticas e culturais vinham ocorrendo, as quais oportunizaram novos arranjos societários, tanto quanto outras sociabilidades e estilos de vida, especialmente urbanos, no 
país. Do ponto de vista econômico, por exemplo, a Revolução de 1930 expressou um projeto social de desenvolvimento da economia, de natureza autônoma, baseado nos crescentes processos de industrialização (Furtado, 2007; Pereira, 1970). As medidas adotadas, em sua maioria, não apenas se interessavam pela manutenção dos índices de emprego e seus níveis de renda, como sua ampliação, através de uma aceleração do mercado produtivo interno, investimentos constantes no mercado de trabalho e o aumento das receitas globais. Esse modelo autônomo de industrialização fez-se antagonista da conhecida política do cafécom-leite, a qual pactuava para um revezamento no controle da política federal, entre mineiros e paulistas, além de promover a ideologia do projeto nacional-desenvolvimentista (Pereira, 1970), em seus estágios germinais. Tais processos impulsionaram a industrialização, com base no mercado interno, o que desencadeou recomposições políticas e econômicas, particularmente observadas com o crescimento demográfico nas áreas urbanas ${ }^{2}$, além da expansão dos contingentes de trabalhadores urbanos que se fortaleciam politicamente. Houve, pois, uma "[...] revolução não-burguesa" (Pereira, 1970, p. 70), paradoxalmente marcada por um movimento popular-citadino, porém sem negação da ordem nascente capitalista, mas reforçando-a. A partir de 1930, ocorreu uma substituição da elite no poder, sem rupturas substanciais, visto que declinaram os quadros oligárquicos tradicionais e ascenderam os militares, os técnicos diplomados, os jovens políticos e, a posteriori, os industriais (Fausto, 2011). Ainda que, segundo Oliven (1980), tenham havido inúmeras revoltas sociais e militares, desde a década de 1920.

O crescimento industrial conduziu a intensas dinâmicas de urbanização, face às migrações internas e, em boa medida, ao êxodo rural, mesmo que isso não tenha removido do horizonte as discursividades da “[...] vocação agrária" do Brasil (Oliven, 1980, p. 30). O deslocamento dos mecanismos de desenvolvimento econômico de uma base agrária para a industrial não se deu sob plena oposição (ou substitutivo), antes, pelo contrário, em situações específicas que os associaram (Oliven, 1980; Pereira, 1970). As populações urbanas ampliaram-se por inúmeros motivos, no entanto, um motivo nos parece fundamental:

[...] (a) atração que a cidade exerce sobre as populações rurais, através da expectativa de melhores condiç̃es de vida e trabalho, o que é fomentado pela constante difusão de imagens e valores urbanos através do país pelos meios de comunicação de massa (Oliven, 1980, p. 68).

A partir deste momento histórico, observamos um aumento das populações urbanas que, poucas décadas depois, conduziria a uma superação quantitativa (em média percentual) das populações habitantes no meio rural (Santos, 2009). Esse amplo conjunto de mudanças sociais exigia novos ordenamentos às ações educacionais, quer seja em suas expectativas de ampliação dos sistemas de atendimento ou da emergência de uma intencionalidade ordenadora. Desse modo, 
Políticas Educativas e a Gestão dos Modos de Viver nas Cidades

[...] a escola primária dos anos 10, 20 e 30, vai se compondo a partir de novas necessidades sociais, que exigem que o ensino seja repensado tanto nos seus fins quanto nos seus meios. E com uma intencionalidade ordenadora cada vez mais explícita, ao se integrar ao projeto político do país, essa nova escola dá início a uma série de ações pedagógicas que têm como objetivo formar novos hábitos e atitudes. É desse período a constituição de pelotões de saúde e do círculo de pais e professores que, com funções muito claras, atuam na escola procurando disseminar um comportamento disciplinador que visa influenciar não apenas os alunos mas, também, as suas famílias (Chaves, 2002, p. 45).

Nesse horizonte, a educação é pensada para além dos muros da escola, com papéis sociais e culturais mais alargados criando condições de possibilidade ao advento da invenção política da educação integral. Educação não mais representaria o ensino da leitura, da escrita e da contagem, mas interessava-se pelo desenvolvimento de hábitos na criança e ações familiares adequadas e orientadas aos pais. Afora iniciativas importantes e socialmente nobres desenvolvidas por Anísio Teixeira, foi no projeto de implantação do Centro Educacional Carneiro Ribeiro, ou Escola Parque, nos anos de 1950, que alicerça-se a primeira e mais significativa elaboração de uma educação integral em tempo integral como política pública dirigida ao desenvolvimento nacional ${ }^{3}$. Sua finalidade era a implementação de um sistema público articulado de escolas voltadas à formação completa do estudante (dos aspectos cognitivos aos nutricionais) em jornada escolar em tempo integral. Como observou Anísio Teixeira:

\begin{abstract}
A escola primária seria dividida em dois setores, o da instrução, propriamente dita, ou seja da antiga escola de letras, e o da educação, propriamente dita, ou seja da escola ativa. No setor instrução, manter-se-ia o trabalho convencional da classe, o ensino de leitura, escrita e aritmética e mais ciências físicas e sociais, e no setor educação - as atividades socializantes, a educação artística, o trabalho manual e as artes industriais e a educação física (Teixeira, 1959, p. 82).
\end{abstract}

Afora outras nuances operacionais dos ideais de Teixeira, inspirado nas teorias escolanovistas, cabe recuperarmos o fio condutor de nossa análise, qual seja: as implicações entre as intervenções políticoculturais nas reformas urbanas e nas reformas nos indivíduos. Em todo caso, é possível verificarmos que essas políticas educativas ampliam o entendimento de educação para além de suas prerrogativas instrucionais e tentam propor modalidades de vínculo ou de adesão da escola ao seu entorno e, ao fazê-lo, produzem formas de gestão dos modos de viver dos indivíduos, sob pressupostos de higienização, ajustamento de condutas e trabalho para a socialização. 
Uma segunda experiência representativa de educação em tempo integral, no Brasil, foi mobilizada nos anos de 1980 pelos Centros Integrados de Educação Pública (os CIEPs) intelectual e politicamente liderados por Darcy Ribeiro e Leonel Brizola. Em maio de 1985, foi inaugurado o primeiro CIEP na capital do Estado do Rio de Janeiro e, posteriormente, entre continuidades e descontinuidades, foram implantadas 506 escolas com este formato. Segundo muitos de seus analistas, estes centros não apresentaram uma proposta pedagógica inovadora, mas confundiam-se a oportunidade de uma jornada escolar ampliada com atividades assistencialistas. De certo modo, é possível acompanharmos análises que reiteram a existência de um "projeto assistencialista" (Cavaliere; Coelho, 2003) nos CIEPs, cujas ênfases estavam no atendimento às crianças pobres, oferendo alimentação e outros serviços essenciais. Para ilustrar, em pesquisa recentemente realizada com diretores destas instituições no Rio de Janeiro (Cavaliere; Coelho, 2003), ao serem perguntados sobre como pensam seus trabalhos diários, $56 \%$ dos informantes assinalou o cunho educativo existente na escola, outros $44 \%$ assinalou os fatores assistenciais ou de modo exclusivo ou associado ao educacional. Afora evidentes críticas ao paternalismo presente nesta política, os projetos dos CIEPs posicionaram-se a favor da educação e do atendimento social de camadas populacionais pobres em ações estatais sistemáticas, em franca oposição aos crescentes modelos gerenciais neoliberais de desresponsabilização do Estado, no cenário sócio-histórico posterior à abertura política.

A ausência de uma proposta político-pedagógica consistente e o alto custo financeiro da permanência dos estudantes em jornada ampliada fizeram com que a proposição passasse por diversos períodos de continuidade, o que desarticulou o interesse por seus pressupostos, além de uma "[...] perda de identidade dos CIEPS", como observaram Cavaliere e Coelho (2003, p. 173).

Um terceiro momento destas políticas no Brasil refere-se ao Programa Mais Educação, o qual, a nosso ver, posiciona um novo projeto civilizacional à educação brasileira, recuperando pressupostos das duas experiências anteriores e enfrentando novos desafios à gestão e à política educacional brasileira. Assim, se a experiência da Escola Parque preocupava-se com a elevação intelectual da população dirigida ao desenvolvimento nacional e o experimento idealizado por Darcy Ribeiro focava no atendimento prioritário de necessidades sociais essenciais, o Mais Educação encontrará outros horizontes de preocupação societária e o compromisso de construção de uma nova identidade à escola brasileira. Não obstante às diferenças entre as experiências citadas, cabe destacar que a educação em tempo integral como política pública voltada à formação global do indivíduo torna-se repositório de novas expectativas educativo-culturais, que, desde sua efetuação, se evidenciam desafios às políticas públicas de cada tempo histórico, mas, por vezes, com objetivos similares, como: a ampliação da infraestrutura das escolas, a qualificação de professores e a redefinição das diretrizes de

Educação \& Realidade, Porto Alegre, v. 38, n. 3, p. 953-975, jul./set. 2013.

Disponível em: <http://www.ufrgs.br/edu_realidade> 
Políticas Educativas e a Gestão dos Modos de Viver nas Cidades

ação aos agentes e gestores envolvidos. Há, pois, concepções educativas e político-culturais em jogo em cada um destes novos projetos.

O Programa Mais Educação foi instituído pelas Portarias Normativas Interministeriais $n^{\circ} 17$ e $n^{\circ} 19$, de 24/04/2007. Este programa, segundo sua normatização oficial, tem por objetivo "[...] fomentar a educação integral por meio do apoio a atividades socioeducativas no contra-turno escolar" (Brasil, 2009). O objetivo desta iniciativa traz novamente à pauta nacional um conceito de educação integral em tempo integral.

Embora este não seja um termo novo, pois, do ponto de vista de seus fundamentos teórico-filosóficos, educação integral é uma ideia que correntes modernas no pensamento pedagógico já haviam elaborado, mesmo que de modo distinto ${ }^{4}$, tampouco faz-se novidade desde sua operacionalização política ou de sua base normatiza, pois há inúmeros registros de experiências políticas implementadas ${ }^{5}$ e de proposições legais ${ }^{6}$ que, desde a constituição de 1988, apontam a esta direção. No entanto, o Programa Mais Educação, em boa medida, atualiza o conceito de educação integral, voltado para dimensões, como: a ampliação e qualificação do espaço escolar, a ampliação do tempo de permanência do aluno na escola e o reconhecimento das múltiplas relações pedagógicas que se tecem entre a escola e a comunidade que a circunda ( Brasil, 2009). Há, enquanto pressuposto político, a ampliação das esferas de gestão educacional para outros órgãos e setores de governo, co-responsabilizando todos os âmbitos de atuação do Estado pela educação, ampliando, assim, o próprio campo educativo, como o documento informa:

\begin{abstract}
A articulação entre educação, assistência social, cultura e esporte, dentre outras políticas públicas, poderá se constituir como uma importante intervenção para a proteção social, prevendo a situação de violação de direitos da criança e do adolescente, e, também, para a melhoria do desempenho escolar e da permanência na escola, principalmente em territórios mais vulneráveis (Brasil, 2009, p. 35).
\end{abstract}

Face a uma nova ampliação das funções da educação, na contemporaneidade, estas novas políticas educativas inserem na agenda de discussões políticas sobre a temática a preocupação com os nexos entre escola e proteção social. Ao vincular, as práticas de ensino-aprendizagem com as práticas das culturas locais, estas modalidades de programas políticos focam na "formação global dos indivíduos" (Cavaliere, 2002), com um interesse sócio-integrador, fazendo, pois, uso da cultura como meio ou instrumento de proteção social. O princípio de ampliação do tempo escolar, assim, prevê a proposição de atividades diversificadas a serem realizadas no contra-turno das atividades escolares regulares, as quais acabam sendo ocupadas por atividades desportivas, lúdicas e culturais - o que expressa a mútua determinação e gestão dos Ministérios da Educação, da Cultura, do Esporte e do Desenvolvimento Social e Combate à Fome. Ou seja, a formação cultural dos atores encontra, politicamente, novas condições de possibilidade.

968 Educação \& Realidade, Porto Alegre, v. 38, n. 3, p. 953-975, jul./set. 2013

Disponível em: <http://www.ufrgs.br/edu_realidade> 


\section{A Reconstrução de Narrativas de Sentido Social: os desafios da gestão}

De certo modo, a ideia de crise da escola é uma recorrência em diversos estudos (Momo; Costa, 2009), mas, em nossa leitura, isso evidencia indícios do declínio de sua institucionalidade, o que tem possibilitado a presença de vários projetos culturais nas instituições. A fragilização de alguns princípios basilares da escola moderna, como suas prerrogativas de santuário do conhecimento, permitem aproximações de projetos de distintas origens, os quais usam a escola para finalidades de mercado (Momo; Costa, 2009), outros, cuja gênese e desenvolvimento encontram-se no Estado, visibilizam nestes projetos culturais tanto ações de construção de cidadania, quanto um potencial de proteção social. Em todo caso, nos parece que a cultura tem sido usada convenientemente para promover a cidadania na escola, o que acompanharia toda uma tendência contemporânea.

As elaborações recentes de George Yúdice (2004) mencionam que a cultura tem redefinido projetos societários, trajetórias individuais, formulações de planos e políticas, mobilizações de recursos, emergência ou centralidade de outras instituições nestes campos, direitos e possibilidades de ação política. No Brasil, essa tendência assume relevância de inúmeras formas, sobretudo nas ênfases dadas às mutações observadas no emprego do termo cultura, em suas políticas e práticas sociais, o que adquire importantes ressonâncias nos documentos recentes da UNESCO. Um marco nestes documentos é o Relatório da Comissão Mundial de Cultura e Desenvolvimento que dissemina os usos da cultura como fator de desenvolvimento das comunidades. Ou, posteriormente, já no caso brasileiro, explicitado no Seminário Internacional sobre Políticas Culturais para o Desenvolvimento realizado em parceria entre o IPEA (Instituto de Pesquisa Econômica Aplicada) e a UNESCO, em Recife, em 2002. Segundo esse argumento, podemos compreender que a cultura não possui uma essência ou um sentido pré-fixado, como supunham os pensadores modernos, antes, por outro lado, elabora-se nas práticas sociais, sendo usada de diferentes modos, para diferentes finalidades. $\mathrm{O}$ que intensifica-se nos tempos atuais, quando a cultura passa a ter centralidade em inúmeras proposições políticas, econômicas e societárias, oras como potencializadora de iniciativas de combate às desigualdades sociais, outras vezes como instrumento de geração de emprego e renda, outras ocasiões vinculando-se à educação em projetos focados na formação de atores culturais ou na construção da cidadania, como também sinaliza a experiência do Programa Mais Educação.

Em movimento similar, embora aparentemente por finalidade distinta, a cultura assume estatuto de política sistemática do Estado Brasileiro, em contrário às iniciativas políticas difusas e pouco consistentes que vinham ocorrendo desde o primeiro governo de Getúlio Vargas. Com estas alterações no estatuto hodierno da cultura, multiplicam-se ações de governo, estudos e pesquisas públicas e privadas sobre

Educação \& Realidade, Porto Alegre, v. 38, n. 3, p. 953-975, jul./set. 2013.

Disponível em: <http://www.ufrgs.br/edu_realidade> 969 
Políticas Educativas e a Gestão dos Modos de Viver nas Cidades

o tema. Há, portanto, uma convergência de percepções entre inúmeros pesquisadores acerca da centralidade das políticas culturais em projetos societários na contemporaneidade, ou seja, há um conjunto de alterações contemporâneas que permitem o advento dessas políticas (públicas ou não) de cultura. Em linhas gerais, citamos como exemplares das transformações socioculturais na atualidade e, ao mesmo tempo, caracterizando-as: o declínio e as mutações das instituições e a emergência de ações sociais regidas por princípios heterogêneos que constituem as experiências sociais (Dubet, 1994); as novas reivindicações políticas por direitos culturais, tendo por expoentes as demandas das mulheres (Touraine, 2007); a emergência de uma nova questão social, tendo por aporia fundamental a coesão social, indo além das relações clássicas de capital-trabalho (Castel, 2004); o crescimento a politização das diferenças culturais no bojo de sociedades democráticas (Wieviorka, 2006); a constituição de coletividades ambivalentes, tendo no horizonte de suas reivindicações reconhecimento e redistribuição (Fraser, 2001); as novas definições e modulações das políticas de cultura na contemporaneidade; a visibilidade de processos sociais de exclusão e seus novos condicionamentos sociais (Lopes, 2008), dentre outros.

Essa nova dinâmica das políticas de cunho cultural expandiu-se para além de seu setor de governo e alcança, de modo intersetorial, outras áreas da ação do Estado: educação, saúde, esporte e lazer, produzindo exigências e condições para novas políticas da educação. Estas novas políticas, cuja situação do Programa Mais Educação é exemplar, projetam objetivos que excedem a formação escolar convencional e tangenciam outras pretensões para as experiências de escolarização institucionalizada, nomeadamente formação cultural e construção da cidadania, como demonstramos.

Neste sentido, com a maior amplitude ou abrangência destas políticas educativas, novas narrativas de sentido social passam a circular entre seus agentes e suas prerrogativas institucionais oportunizando a irradiação de agenciamentos culturais diversificados, mas, por outro lado, outros campos valorativos compartilhados passam a constituirse (Silva, 2012). A fragilização dos aportes de instituição moderna, paradoxalmente, dá condições para a emergência de valores democráticos (Dewey, 1970) e a produção de campo fértil ao reconhecimento das diferenças culturais, porque a escola não mais operaria sob interesses universalistas e monoculturais, mas estaria atenta às mudanças político-culturais vividas. Se nossa hipótese for coerente, essa situação potencializa três desafios à gestão educativa contemporânea.

Finalizaremos este artigo, produzindo um sumário destes desafios, mesmo considerando a necessidade de melhor investigá-los, posteriormente.

a) A cidadania parece ser a grande narrativa discursiva da modernidade, vista pela invenção da ideia de direitos, mas também pela recuperação do primado greco-romano do pertencimento a uma uni- 
dade nacional. As políticas educativas, durante longos ciclos históricos, efetuadas até meados do século passado, assentavam em princípios integradores de homogeneidade, sob princípios formativos lineares, autocentrados e civilizadores, de maneira que os laços de pertencimento do cidadão a uma coletividade, ou cidade, estava condicionada aos modos como internalizava suas normas (Durkheim, 1987). As políticas da educação operavam com a produção de sujeitos voltados a determinados objetivos nacionais, o que não difere das pautas destas políticas no Brasil, onde a ideia de educação integral torna-se uma questão nacional. Assim, associam-se à gestão das cidades, formas de regulação dos modos de vida dos indivíduos em suas tramas de sentido, pois a educação estava pensada para além dos processos escolares. No caso brasileiro recente, inúmeras discursividades políticas foram mobilizadas associando educação ao desenvolvimento nacional, ao combate das desigualdades sociais, à construção de uma sociedade das proteções ou mesmo de construção de costumes ou de virtudes cívicas, mas a todo tempo, diante da fragilização dos dispositivos institucionais, estiveram entrecruzadas por narrativas de sentido social, tendo a cidadania como sua expressão basilar. No entanto, ao mesmo tempo, estas narrativas mobilizam agenciamentos culturais diversos que passam a permear as escolas, estes com conteúdo heterogêneo, inclinado a percepções identitárias multiculturais e ao reconhecimento de práticas democráticas em seu cotidiano. O primeiro desafio é a compreensão da multiplicidade de atores constituintes dos universos escolares e a produção de uma gestão das diversidades, sem o interesse de homogeneizá-las, mas, ao reconhecer suas ações, disputas e clivagens, estabelecer dispositivos de negociação entre a institucionalidade e as alteridades distintas.

b) Os indícios da presença de múltiplos agenciamentos culturais nas políticas educativas contemporâneas apontam para a produção de discursos institucionais não mais coerentes, coesos e autorreferentes, ou seja, não sabemos mais se é possível a produção de posições políticas internas consensuais ou harmonizadas. Parece-nos que as contradições, ambiguidades e ambivalências tecem as argumentações endógenas à escola e tangenciam relações exógenas, com o entorno, com a cidade, com o Estado. Neste horizonte, observamos o segundo desafio, qual seja: a produção de uma gestão efetivamente democrática, onde interesses ideológicos e representações idealizadas de participante e de processo, deem lugar a constantes aprendizados da vida democrática, em outros “[...] dispositivos culturais de deliberação" (Dewey, 1970, p. 100). As narrativas políticas consequentes das três experiências de educação em tempo integral presentes na seção textual anterior são díspares entre si, entretanto salvaguardam o princípio anisiano de educação como direito (Teixeira, 1977) e da necessidade de reconstrução das bases para uma convivência democrática.

c) As experiências em curso exigem outras práticas de gestão escolar, que reflitam sobre as condições possíveis de institucionalidade da escola e seus múltiplos usos na contemporaneidade, interrogan-

Educação \& Realidade, Porto Alegre, v. 38, n. 3, p. 953-975, jul./set. 2013.

Disponível em: <http://www.ufrgs.br/edu_realidade> 
Políticas Educativas e a Gestão dos Modos de Viver nas Cidades

do-se permanentemente, como o fez Cavaliere (2002), sobre as novas identidades da/para a escola brasileira. O que, portanto, representaria a desafiadora provocação de uma gestão das identidades escolares e das identificações de seus atores, esta atenta ao limite de não se tornar uma máquina que fabrica identidades sociais, mas que potencialize processos de formação cultural nos diálogos entre o local e o global, o individual e o coletivo, a estrutura e as formas de ação, a tradição e a inovação, a escola e a cidade. Aqui, a nosso ver, situa-se um pertinente lócus para interrogações futuras às políticas de educação integral em tempo integral.

Recebido em 27 de março de 2012 Aprovado em 22 de novembro de 2012

\section{Notas}

1 As revisões realizadas por Coelho; Cavaliere (2002); Menezes (2009); Pinheiro (2009); Coelho (2009) são elucidativas quanto ao debate social e pedagógico implicado nas categorias educação integral e tempo integral. Educação integral representa, mesmo diante de suas distintas abordagens, a percepção de um projeto formativo que vislumbra interesses na multidimensionalidade da formação do indivíduo ou, nos termos de Anísio Teixeira, sua "formação completa". Tempo integral representa o interesse em ampliação no tempo de permanência do estudante na escola, ou a ampliação da jornada escolar. A literatura indica uma relativa autonomia entre as duas situações, de modo que se faz possível observar recorrências de educação integral, mesmo sem nenhum apontamento ao tempo integral e vice-versa. Entretanto, as três experimentações políticas narradas nesta inflexão analítica associam educação integral e tempo integral, de modo que, na maior parte das circunstâncias, utilizaremos educação integral em tempo integral.

2 Todas as cidades brasileiras cresciam, especialmente no intervalo das décadas de 1890 a 1900. No entanto, o ritmo acelerado que os anos de 1930 evidenciaram ficou restrito às regiões metropolitanas das regiões Sul e Sudeste, com intensidade em São Paulo e no Rio de Janeiro (Fausto, 2011), o que permite constatarmos seu caráter heterogêneo e desigual quanto ao crescimento demográfico.

3 Se, por um lado, as reformas educacionais realizadas nos primeiros anos do Século XX oportunizam homologias ao processo civilizador narrado por Elias (2011); o Centro Educacional Carneiro Ribeiro, por outro, indica-nos que tal processo, em nosso país, não estaria isento de objetivos sociais para o setor.

4 Pinheiro (2009) fez uma revisão importante destas tendências político-pedagógicas modernas que trataram do conceito de educação integral, nomeadamente conservadores, socialistas e liberais.

5 Experiências estas que, em sua maioria, se dão em esferas municipais, conforme Coelho (2009).

6 Neste sentido, ver Menezes (2009). 


\section{Referências}

BERGER, Peter; BERGER, Brigitte. O que é uma Instituição Social? In: FORACHI, Marialice Mencarini; MARTINS, José de Souza. Sociologia e Sociedade: leituras de introdução à sociologia. Rio de Janeiro: LTC, 1977. P. 163-168.

BRASIL. Ministério da Educação. Educação Integral: texto referência para o debate nacional. Brasília, 2009. (Série Mais Educação).

CÂNDIDO, Antônio. A Estrutura da Escola. In: FORACCHI, Marialice Mencarini; PEREIRA, Luiz. Educação e Sociedade: leituras de sociologia da educação. 6. ed. São Paulo: Companhia Editora Nacional, 1971.

CARVALHO, José Murilo. Cidadania no Brasil: um longo caminho. 14. ed. Rio de Janeiro: Civilização Brasileira, 2011.

CASTEL, Robert. As Transformações da Questão Social. In: BELFIORE-WANDERLEY, Mariangela; BÓGUS, Lúcia Maria; YASBEK, Maria Carmelita. Desigualdade e a Questão Social. 2. ed. São Paulo: Educ, 2004.

CAVALIERE, Ana Maria. Entre o Pioneirismo e o Impasse: a reforma paulista de 1920. Educação e Pesquisa, São Paulo, v. 29, n. 1, p. 27-44, 2003.

CAVALIERE, Ana Maria. Educação Integral: uma nova identidade para a escola brasileira? Educação e Sociedade, Campinas, v. 23, n. 81, p. 247-270, 2002.

CAVALIERE, Ana Maria; COELHO, Lígia Martha. Para Onde Caminham os CIEPS? Uma análise após 15 anos. Cadernos de Pesquisa, São Paulo, n. 119, p. 147-174, 2003.

CHAVES, Miriam. Educação Integral: uma proposta de inovação pedagógica na administração escolar de Anísio Teixeira no Rio de Janeiro nos anos 30. In: COELHO, Lígia Martha; CAVALIERE, Ana Maria (Org.). Educação Integral e(m) Tempo Integral. Petrópolis: Vozes, 2002. P. 43-60.

COELHO, Lígia Martha; CAVALIERE, Ana Maria (Org.). Educação Integral e(m) Tempo Integral. Petrópolis: Vozes, 2002.

COELHO, Lígia Martha (Org.). Educação Integral em Tempo Integral: estudos e experiências em processo. Petrópolis: DP\&A/Faperj, 2009.

DEWEY, John. Liberalismo, Liberdade e Cultura. São Paulo: Editora Nacional/ USP, 1970.

DUBET, François. As Desigualdades Multiplicadas. Ijuí: UNIJUÍ, 2003.

DUBET, François. Conflictos de Normas y Ocaso de la Institución. Estudios Sociológicos, México, v. 22, n. 64, p. 3-24, 2004.

DUBET, François. El Declive y las Mutaciones de la Instituición. Revista de Antropología Social, Madrid, n. 16, p. 39-66, 2007.

DUBET, François. Sociologia da Experiência. Lisboa: Instituto Piaget, 1994.

DURKHEIM, Emile. A Educação Como Processo Socializador: função homogeneizadora e função diferenciadora. In: FORACCHI, Marialice Mencarini; PEREIRA, Luiz. Educação e Sociedade: leituras de sociologia da educação. 13. ed. São Paulo: Companhia Editora Nacional, 1987.

ELIAS, Norbert. O Processo Civilizador: uma história dos costumes. 2. ed. Rio de Janeiro: Zahar, 2011. Volume 1.

ELIAS, Norbert. O Processo Civilizador: formação do Estado e civilização. Rio de Janeiro: Zahar, 1993. Volume 2.

FAUSTO, Boris. História Concisa do Brasil. 2. ed. São Paulo: Edusp, 2011.

Educação \& Realidade, Porto Alegre, v. 38, n. 3, p. 953-975, jul./set. 2013

Disponível em: <http://www.ufrgs.br/edu_realidade> 
Políticas Educativas e a Gestão dos Modos de Viver nas Cidades

FRASER, Nancy. Da Redistribuição ao Reconhecimento? Dilemas da justiça na era pós-socialista. In: SOUZA, Jessé (Org.). Democracia Hoje. Brasília: Ed. UNB, 2001.

FURTADO, Celso. Formação Econômica do Brasil. 34. ed. São Paulo: Companhia das Letras, 2007.

LOPES, José Rogério. Processos Sociais de Exclusão e Políticas Públicas de Enfrentamento da Pobreza. Cadernos CRH, Salvador, v. 21, n. 53, p. 349-363, 2008.

MENEZES, Janaína Specht Silva. Educação Integral e Tempo Integral na Educação Básica: da LDB ao PDE. In: COELHO, Lígia Martha. (Org.) Educação Integral em Tempo Integral: estudos e experiências em processo. Petrópolis: DP\&A/Faperj, 2009. P. 69-87.

MOMO, Mariangela; COSTA, Marisa Vorraber. Sobre a "Conveniência" da Escola. Revista Brasileira de Educação, Rio de Janeiro, v. 14, n. 42, p. 521-533, 2009.

OLIVEN, Ruben. Urbanização e Mudança Social no Brasil. Petrópolis: Vozes, 1980.

PEREIRA, Luiz. Ensaios de Sociologia do Desenvolvimento. São Paulo: Pioneira, 1970.

PINHEIRO, Fernanda Picanço Silva Zarour. Programa Mais Educação: uma concepção de educação integral. 2009. Dissertação (Mestrado em Educação) - Programa de Pós-Graduação em Educação, Centro de Ciências Humanas e Sociais, Universidade Federal do Estado do Rio de Janeiro (UNIRIO), Rio de Janeiro, 2009.

SANTOS, Milton. A Urbanização Brasileira. 5. ed. São Paulo: Edusp, 2009.

SILVA, Rodrigo Manoel Dias da. Experiências Sociais e Lógicas de Ação Política: etnografia da participação estudantil na escola pública. 2008. Dissertação (Mestrado em Ciências Sociais) - Programa de Pós-Graduação em Ciências Sociais. Universidade do Vale do Rio dos Sinos (UNISINOS), São Leopoldo, 2008.

SILVA, Rodrigo Manoel Dias da. Políticas Culturais em Cidades Turísticas Brasileiras: um estudo sobre as técnicas de vida contemporâneas. 2012. Tese (Doutorado em Ciências Sociais) - Programa de Pós-Graduação em Ciências Sociais. Universidade do Vale do Rio dos Sinos (UNISINOS), São Leopoldo, 2012.

SIMMEL, Georg. Cultura Femenina y Otros Ensayos. 5. ed. Buenos Aires: Espasa-Calpe, 1946.

TEIXEIRA, Anísio. Centro Educacional Carneiro Ribeiro. Revista Brasileira de Estudos Pedagógicos, Rio de Janeiro, v. 31, n. 73, p. 78-84, 1959.

TEIXEIRA, Anísio. Educação não é Privilégio. 4. ed. São Paulo: Companhia Editora Nacional, 1977.

TIRAMONTI, Guillermina. La Escuela en la Encrucijada del Cambio Epocal. Educação e Sociedade, Campinas, v. 26, n. 92, p. 889-910, 2005.

TOFLER, Alvin. O Povo e a Cultura. Rio de Janeiro: Lidador, 1964.

TOPALOV, Christian. Da Questão Social aos Problemas Urbanos: os reformadores e a população das metrópoles em princípios do século XX. In: RIBEIRO, Luiz César Q.; PECHMAN, Robert (Org.). Cidade, Povo e Nação. Rio de Janeiro: Civilização Brasileira, 1996. P. 23-52.

TOURAINE, Alain. Um Novo Paradigma Para Compreender o Mundo de Hoje. São Paulo: Vozes, 2007.

WIEVIORKA, Michel. Em que Mundo Viveremos? São Paulo: Perspectiva, 2006 
YUDICE, George. A Conveniência da Cultura: usos da cultura na era global. Belo Horizonte: Editora UFMG, 2004.

ZNANIECKI, Florian. A Escola Como um Grupo Instituído. In: FORACCHI, Marialice M.; PEREIRA, Luiz. Educação e Sociedade: leituras de sociologia da educação. 6. ed. São Paulo: Companhia Editora Nacional, 1971.

Rodrigo Manoel Dias da Silva é professor de Sociologia na Universidade Federal da Fronteira Sul, Campus Erechim. Doutor em Ciências Sociais (UNISINOS), Mestre em Ciências Sociais (UNISINOS) e Licenciado em Pedagogia (UERGS). Pesquisador vinculado ao grupo de pesquisa Educação, Culturas e Políticas Contemporâneas.

E-mail: rodrigoddsilva@hotmail.com

Chaiane Paula Busnello é acadêmica do curso de Licenciatura em Pedagogia na Universidade Federal da Fronteira Sul, Campus Erechim. Bolsista de Iniciação Científica.

E-mail: chai_busnello@hotmail.com

Fabíola Pezenatto é acadêmica do curso de Licenciatura em Ciências Sociais na Universidade Federal da Fronteira Sul, Campus Erechim. Bolsista de Iniciação Científica.

E-mail: fabypezenatto@yahoo.com.br 